\title{
O PACTO NACIONAL PELA ALFABETIZAÇÃO NA IDADE CERTA E A RESPONSABILIZAÇÃO (ACCOUNTABILITY) DO PROFESSOR ALFABETIZADOR
}

\author{
EL PACTO NACIONAL POR LA ALFABETIZACIÓN EN LA EDAD CIERTA Y \\ LA RESPONSABILIZACION (ACCOUNTABILITY) DEL PROFESOR \\ ALFABETIZADOR
}

\author{
THE NATIONAL PACT FOR LITERACY AT PROPER AGE AND \\ ACCOUNTABILITY OF LITERACY TEACHER
}

\author{
Rosimar Serena Siqueira ESQUINSANI ${ }^{1}$
}

RESUMO: O texto apresenta pesquisa sobre o Pacto Nacional pela Alfabetização na Idade Certa - PNAIC enquanto mobilizador de ações em torno da alfabetização, através de estratégias de formação docente continuada e controle social. Entende-se que o Pacto assume dupla função: fornecer subsídios formativos ao professor e, em contrapartida, colocá-lo como sujeito central da responsabilização sobre os resultados em relação aos processos para os quais foi formado, materializando o accountability como estratégia de política educacional. Para elaboração dos argumentos, foi utilizada metodologia quali/quantitativa com foco analítico-reconstrutivo, desenvolvida a partir da análise de conteúdo em relação a documentos de gestão da educação. O corpus documental foi constituído a partir da reunião de documentos divididos em duas ordens: documentos que justificam o Pacto e documentos que configuram o PNAIC. O Pacto apresenta uma fórmula de responsabilização: meta (alfabetização das crianças até os 8 anos de idade) versus aporte técnico e financeiro (estabelecimento de rotas formativas associadas a bolsas de apoio) versus cobrança de resultados (desempenho em avaliações em larga escala), associada ao accountability. Conclui-se que o Pacto legitima a formação docente continuada como estratégia de repasse do accountability, colocando o professor alfabetizador como coadjuvante no processo de formação, mas como protagonista na responsabilização.

PALAVRAS-CHAVE: Alfabetização. Pacto Nacional pela alfabetização na idade certa. Formação docente continuada. Accountability.

RESUMEN: El texto presenta una investigación sobre el "Pacto Nacional por la Alfabetización en la Edad Cierta" - PNAIC - como movilizador de acciones sobre la alfabetización, por medio de estrategias de formación docente continua y control social. Se entiende que el Pacto asume doble función: fornecer condiciones formativas al profesor y, en contrapartida, ponerlo como sujeto central de la responsabilización sobre los resultados respecto a los procesos para los cuales fue formado, materializando el accountability como estrategia de política educacional. Para elaboración de los argumentos, fue utilizada metodología cuali/cuantitativa con foco analítico-reconstructivo, desarrollada a partir de análisis de contenido en relación a documentos de gestión de la educación. El corpus documental fue constituido a partir de la reunión de documentos divididos en dos tipos: documentos que justifican el Pacto

${ }^{1}$ Doutora em Educação. Pesquisadora e Professora de Educação. Faculdade de Educação - Faed/UPF. Programa de Pós-Graduação em Educação, Passo Fundo, Brasil. E-mail: rosimaresquinsani@upf.br. 
y documentos que configuran el PNAIC. El Pacto presenta una fórmula de responsabilización: meta (alfabetización de los niños hasta los 8 años de edad) versus aporte técnico y financiero (establecimiento de rutas formativas asociadas a becas de apoyo) versus exigencia de resultados (desempeño en evaluación en larga escala), asociada al accountability. Se concluye que el Pacto legitima la formación docente continua como estrategia de repase de accountability, poniendo el profesor alfabetizador como coadjuvante en el proceso de formación, pero como protagonista en la responsabilización.

PALABRAS CLAVE: Alfabetización. Pacto Nacional por la alfabetización en la edad certa. Formación docente continua. Accountability.

ABSTRACT: The paper presents a survey of the National Pact for literacy at proper age - PNAIC as mobilizer actions around literacy, through strategies of continuing teacher training and social control. It is understood that the pact takes dual role: to provide training grants to the teacher and, in turn, put it as the central subject of the accountability of the results of the processes for which it was formed, materializing the accountability as educational policy strategy. For preparation of arguments was used qualitative / quantitative methodology with analytical-reconstructive focus, developed from the content analysis in relation to education management documents. The documentary corpus was formed from the meeting document management divided into two types: documents justifying the Pact and documents that contribute the PNAIC. The Pact presents an accountability formula: target (children literacy to 8 years old) $X$ technical and financial support (establishment of training routes associated with support grants) $X$ collection of results (performance in large-scale assessments) associated to accountability. We conclude that the pact legitimizes continuing teacher training and accountability of the transfer strategy, putting the teacher literacy as an aid in the training process, but as the protagonist accountability.

KEYWORDS: Literacy. The National Pact for literacy at proper age. Continuing teacher formation. Accountability

\section{Introdução}

O texto expressa resultados de uma pesquisa sobre o Pacto Nacional pela Alfabetização na Idade Certa - PNAIC enquanto mobilizador de ações pedagógicas em torno da alfabetização, através de estratégias de formação docente continuada e controle social. Por esse ângulo interpretativo, entende que o Pacto assume uma dupla função: fornecer subsídios formativos ao professor e, em contrapartida, colocá-lo como sujeito central da responsabilização dos resultados dos processos para os quais foi formado, materializando o accountability como estratégia de política educacional.

Para elaboração dos argumentos desenvolvidos no texto, foi utilizada metodologia quali/quantitativa com foco analítico-reconstrutivo, desenvolvida a partir 
do procedimento de análise de conteúdo em relação a documentos de gestão da educação.

Os documentos foram examinados a partir da metodologia da análise de conteúdo, utilizando-se a técnica da análise temática, onde o "[...] tema é a unidade de significação que se liberta naturalmente de um texto analisado, segundo critérios relativos à teoria que serve de guia à leitura." (BARDIN, 2007, p.105). O corpus documental foi constituído a partir da reunião de documentos de gestão (leis, decretos, portarias, resoluções [...]) divididos em duas ordens: documentos que justificam o Pacto e documentos que configuram o PNAIC.

Cabe destacar que o texto apresentado é parte integrante de um contexto amplo de pesquisa, que objetiva contribuir para a discussão de políticas e mecanismos institucionais de gestão da educação em redes e sistemas públicos de ensino, enquanto pauta candente na composição da atual agenda educacional.

\section{Situando a questão}

Há uma miríade de programas de governo e movimentos/ações - em todas as esferas do poder público - lançados em torno da formação de professores para os anos iniciais de escolarização, alguns deles com ênfase específica na alfabetização. O alcance de cada programa depende, em grande medida, da capacidade de mobilização do mesmo em torno de objetivos concretamente articulados com o cotidiano escolar, além dos critérios e condições de pactuação do programa em relação aos possíveis parceiros (envolvimento, contrapartida, financiamento [...]).

Dentre tais programas, citamos o PROFA - Programa de Formação de Professores Alfabetizadores, uma iniciativa do Ministério da Educação no início dos anos 2000, executado através da Secretaria de Educação Fundamental (BRASIL, 2001); o Pró-Letramento (BRASIL, 2006b), ação do Ministério da Educação e Cultura /MEC, no âmbito da Secretaria de Educação Básica /SEB e em parceria com Universidades, Estados e Municípios, e - nosso objeto de estudo - o Pacto Nacional pela Alfabetização na Idade Certa - PNAIC (BRASIL, 2012b). 
O Pacto Nacional pela Alfabetização na Idade Certa é um compromisso formal assumido pelos governos federal, do Distrito Federal, dos estados e municípios de assegurar que todas as crianças estejam alfabetizadas até os oito anos de idade, ao final do $3^{\circ}$ ano do ensino fundamental.

As bases legais que justificam a instituição do PNAIC são descritas como: Lei 9.394/1996 (BRASIL, 1996); Lei 11.273/2006 (BRASIL, 2006a); Decreto no. 6.094 de

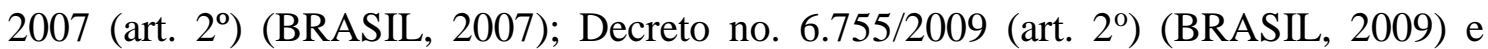
Decreto no. 7.084/2010 (art. 1, parágrafo único) (BRASIL, 2010). A partir desse conjunto de documentos legitima-se o Pacto Nacional pela Alfabetização na Idade Certa - PNAIC (BRASIL, 2012b).

Tabela 01 - Bases legais que justificam a instituição do PACTO

\begin{tabular}{|c|c|}
\hline Legislação & Ementa \\
\hline $\begin{array}{l}\text { Lei no. 9.394, de } 20 \text { de } \\
\text { dezembro de } 1996 \\
\text { (BRASIL, 1996) }\end{array}$ & Estabelece as diretrizes e bases da educação nacional. \\
\hline $\begin{array}{l}\text { Lei } \mathrm{n}^{\circ} 11.273, \text { de } 6 \text { de } \\
\text { fevereiro de } 2006 \text { (BRASIL, } \\
\text { 2006a) }\end{array}$ & $\begin{array}{l}\text { Autoriza a concessão de bolsas de estudo e de pesquisa a } \\
\text { participantes de programas de formação inicial e continuada } \\
\text { de professores para a educação básica. }\end{array}$ \\
\hline $\begin{array}{l}\text { Decreto } \mathrm{n}^{\circ} 6.094, \text { de } 24 \text { de } \\
\text { abril de } 2007 \text { (BRASIL, } \\
\text { 2007) }\end{array}$ & $\begin{array}{l}\text { Dispõe sobre a implementação do Plano de Metas } \\
\text { Compromisso Todos pela Educação, pela União Federal, em } \\
\text { regime de colaboração com Municípios, Distrito Federal e } \\
\text { Estados, e a participação das famílias e da comunidade, } \\
\text { mediante programas e ações de assistência técnica e } \\
\text { financeira, visando à mobilização social pela melhoria da } \\
\text { qualidade da educação básica. }\end{array}$ \\
\hline $\begin{array}{l}\text { Decreto } \mathbf{n}^{\mathbf{0}} \mathbf{6 . 7 5 5} \text {, de } 29 \text { de } \\
\text { janeiro de } 2009 \text {. } \\
\text { (Revogado pelo Decreto } \mathrm{n}^{\circ} \\
8.752 \text {, de 2016) (BRASIL, } \\
\text { 2009) }\end{array}$ & $\begin{array}{l}\text { Institui a Política Nacional de Formação de Profissionais do } \\
\text { Magistério da Educação Básica, disciplina a atuação da } \\
\text { Coordenação de Aperfeiçoamento de Pessoal de Nível } \\
\text { Superior - CAPES no fomento a programas de formação } \\
\text { inicial e continuada, e dá outras providências. }\end{array}$ \\
\hline $\begin{array}{l}\text { Decreto n } 7.084 \text { de } 27 \text { de } \\
\text { janeiro de } 2010 \text { (BRASIL, } \\
\text { 2010) }\end{array}$ & $\begin{array}{l}\text { Dispõe sobre os programas de material didático e dá outras } \\
\text { providências. }\end{array}$ \\
\hline
\end{tabular}

Fonte: Elaboração própria.

Diferentes componentes dessas legislações são utilizados como justificativa para o Pacto. A Lei $n^{\circ}$ 11.273/2006 (BRASIL, 2006a), sobre a concessão de bolsas de estudos para professores da educação básica - uma das estratégias do Pacto, referendado pelo Decreto $\mathbf{n}^{\mathbf{0}} \mathbf{6 . 7 5 5 / 2 0 0 9}$ (BRASIL, 2009), que instituiu a Política Nacional de Formação de Profissionais do Magistério da Educação Básica; o 
Decreto $n^{\circ}$ 6.094/2007 (BRASIL, 2007) - Plano de Metas Compromisso Todos pela Educação, reafirmando o regime de colaboração entre os entes federados em prol de objetivos educacionais socialmente relevantes, com ênfase na diretriz II: “[...] alfabetizar as crianças até, no máximo, os oito anos de idade, aferindo os resultados por exame periódico específico" - Art. 2 (BRASIL, 2007), e o Decreto n 7.084/2010 (BRASIL, 2010), sobre material didático. Da LDB vários artigos emprestam justificativas ao Pacto, com relevo para os artigos que mencionam a formação docente continuada (art. 13; art. 67; art. 87 (BRASIL, 1996)).

Assim, o PNAIC consubstanciou-se como uma ação de atendimento a diferentes perspectivas legais anteriores, como a formação docente continuada enquanto estratégia de metas educacionais e a alfabetização como foco. Tal perspectiva fica evidente nas legislações que aportam o Pacto, instruindo e normatizando o seu funcionamento.

Tabela 2 - Bases legais que aportam o Pacto Nacional pela Alfabetização na Idade Certa - PNAIC (BRASIL, 2012b)

\begin{tabular}{|c|c|}
\hline Legislação & Ementa \\
\hline $\begin{array}{l}\text { Portaria } \mathrm{n}^{\circ} 867 \text {, de } 4 \text { de julho } \\
\text { de } 2012 \text { (Publicado no DOU } \mathrm{n}^{\text {o }} \\
\text { 129, quinta-feira, } 5 \text { de julho de } \\
\text { 2012) (BRASIL, 2012c) }\end{array}$ & $\begin{array}{l}\text { Institui o Pacto Nacional pela Alfabetização na Idade } \\
\text { Certa e as ações do Pacto e define suas diretrizes gerais. }\end{array}$ \\
\hline $\begin{array}{l}\text { Medida Provisória } \mathrm{n}^{\circ} \text { 586, de } 8 \\
\text { de novembro de } 2012 \\
\text { (BRASIL, 2012a) }\end{array}$ & $\begin{array}{l}\text { Dispõe sobre o apoio técnico e financeiro da União aos } \\
\text { entes federados no âmbito do Pacto Nacional pela } \\
\text { Alfabetização na Idade Certa, e dá outras providências. }\end{array}$ \\
\hline $\begin{array}{l}\text { Portaria } n^{\circ} 1.458 \text {, de } 14 \text { de } \\
\text { dezembro de } 2012 \text { (publicado } \\
\text { no DOU } \mathrm{n}^{\circ} 243 \text {, terça-feira, } 18 \\
\text { de dezembro de 2012) } \\
\text { (BRASIL, 2012d) }\end{array}$ & $\begin{array}{l}\text { Define categorias e parâmetros para a concessão de bolsas } \\
\text { de estudo e pesquisa no âmbito do Pacto Nacional pela } \\
\text { Alfabetização na Idade Certa, na forma do art. } 2 \text { o, inciso } \\
\text { I, da Portaria MEC n }{ }^{\circ} \text { 867, de } 4 \text { de julho de } 2012 \\
\text { (BRASIL, 2012c). }\end{array}$ \\
\hline $\begin{array}{l}\text { Portaria } \mathrm{n}^{\circ} 90, \text { de } 6 \text { de fevereiro } \\
\text { de } 2013 \text { (publicada no DOU } \mathrm{n}^{\circ} \\
\text { 27, quinta-feira, } 7 \text { de fevereiro } \\
\text { de 2013) (BRASIL, 2013a) }\end{array}$ & $\begin{array}{l}\text { Define o valor máximo das bolsas para os profissionais da } \\
\text { educação participantes da formação continuada de } \\
\text { professores alfabetizadores no âmbito do Pacto Nacional } \\
\text { pela Alfabetização na Idade Certa. }\end{array}$ \\
\hline $\begin{array}{l}\text { Portaria } \mathrm{n}^{\circ} 482 \text {, de } 7 \text { de junho } \\
\text { de } 2013 \text { (publicada no DOU } \mathrm{n}^{\circ} \\
109 \text {, segunda-feira, } 10 \text { de junho } \\
\text { de } 2013 \text { (BRASIL, 2013b) }\end{array}$ & $\begin{array}{l}\text { Dispõe sobre o Sistema de Avaliação da Educação Básica } \\
-\quad \text { SAEB (incorpora a Avaliação Nacional da } \\
\text { Alfabetização - ANA ao sistema) }\end{array}$ \\
\hline $\begin{array}{l}\text { Resolução/CD/FNDE } \mathrm{n}^{\circ} \text { 4, de } \\
27 \text { de fevereiro de } 2013 \\
\text { (BRASIL, 2013c). }\end{array}$ & $\begin{array}{l}\text { Estabelece orientações e diretrizes para o pagamento de } \\
\text { bolsas de estudo e pesquisa para a Formação Continuada } \\
\text { de Professores Alfabetizadores, no âmbito do Pacto } \\
\text { Nacional pela Alfabetização na Idade Certa. }\end{array}$ \\
\hline $\begin{array}{l}\text { Lei n }{ }^{\circ} 12.801 \text {, de } 24 \text { de abril de } \\
\text { 2013. Conversão da Medida }\end{array}$ & $\begin{array}{l}\text { Dispõe sobre o apoio técnico e financeiro da União aos } \\
\text { entes federados no âmbito do Pacto Nacional pela }\end{array}$ \\
\hline
\end{tabular}




\begin{tabular}{|c|c|}
\hline Legislação & Ementa \\
\hline $\begin{array}{l}\text { Provisória n }{ }^{\circ} \text { 586, de } 2012 \\
\text { (BRASIL, 2012a) }\end{array}$ & $\begin{array}{l}\text { Alfabetização na Idade Certa e altera as Leis nos } 5.537 \text {, } \\
\text { de } 21 \text { de novembro de } 1968,8.405 \text {, de } 9 \text { de janeiro de } \\
1992 \text {, e } 10.260 \text {, de } 12 \text { de julho de } 2001 \text {. }\end{array}$ \\
\hline $\begin{array}{l}\text { Resolução/CD/FNDE } \text { n }^{\circ} 12, \text { de } \\
8 \text { de maio de } 2013 \text { (BRASIL, } \\
\text { 2013d) }\end{array}$ & $\begin{array}{l}\text { Altera dispositivos da Resolução CD/FNDE } \text { n }^{\circ} 4 \text {, de } 27 \text { de } \\
\text { fevereiro de 2013, que estabelece orientações e diretrizes } \\
\text { para o pagamento de bolsas de estudo e pesquisa para a } \\
\text { Formação Continuada de Professores Alfabetizadores, no } \\
\text { âmbito do Pacto Nacional pela Alfabetização na Idade } \\
\text { Certa. }\end{array}$ \\
\hline $\begin{array}{l}\text { Resolução/CD/FNDE n }{ }^{\circ} 10, \text { de } \\
4 \text { de dezembro de } 2015 \\
\text { (BRASIL, 2015) }\end{array}$ & $\begin{array}{l}\text { Estabelece orientações, critérios e procedimentos para a } \\
\text { operacionalização da assistência financeira aos estados } \\
\text { das regiões Norte e Nordeste para impressão de material } \\
\text { de formação e apoio à prática docente, com foco na } \\
\text { aprendizagem do aluno da educação básica. }\end{array}$ \\
\hline $\begin{array}{l}\text { Portaria } \mathrm{n}^{\circ} 153 \text {, de } 22 \text { de março } \\
\text { de } 2016 \text { (publicada no DOU n } \\
\text { 56, quarta-feira, } 23 \text { de março } \\
\text { de 2016) (BRASIL, 2016) }\end{array}$ & $\begin{array}{l}\text { Altera a Portaria MEC n }{ }^{\circ} 867 \text {, de } 4 \text { de julho de } 2012 \\
\text { (BRASIL, 2012c), que institui o Pacto Nacional pela } \\
\text { Alfabetização na Idade Certa e amplia as ações do Pacto e } \\
\text { define suas diretrizes gerais. }\end{array}$ \\
\hline $\begin{array}{l}\text { Portaria } \mathrm{n}^{\circ} 154 \text {, de } 22 \text { de março } \\
\text { de } 2016 \text { (publicada no DOU } \mathrm{n}^{\circ} \\
56 \text {, quarta-feira, 23 de março } \\
\text { de 2016) (BRASIL, 2016) }\end{array}$ & $\begin{array}{l}\text { Altera a Portaria MEC n o90, de } 6 \text { de fevereiro de } 2013 \text {, } \\
\text { que define o valor máximo das bolsas para os } \\
\text { profissionais da educação participantes da formação } \\
\text { continuada de professores alfabetizadores no âmbito do } \\
\text { Pacto Nacional pela Alfabetização na Idade Certa. }\end{array}$ \\
\hline $\begin{array}{l}\text { Portaria } n^{\circ} 155 \text {, de } 22 \text { de março } \\
\text { de } 2016 \text { (publicada no DOU } n^{\circ} \\
56 \text {, quarta-feira, } 23 \text { de março } \\
\text { de 2016) (BRASIL, 2016) }\end{array}$ & $\begin{array}{l}\text { Altera a Portaria MEC no } 1.458 \text {, de } 14 \text { de dezembro de } \\
2012 \text {, que define categorias e parâmetros para a concessão } \\
\text { de bolsas de estudo e pesquisa no âmbito do Pacto } \\
\text { Nacional pela Alfabetização na Idade Certa. }\end{array}$ \\
\hline
\end{tabular}

Fonte: Elaboração própria.

Em relação aos documentos que configuram - conduzem, ancoram, normatizam - o Pacto Nacional pela Alfabetização na Idade Certa - PNAIC (BRASIL, 2012b), iniciamos pela Portaria $n^{\circ}$ 867/2012 (BRASIL, 2012c), exarada pelo MEC, considerada a normativa fundadora do Pacto, que traz no artigo $5^{\circ}$, os objetivos das ações do Pacto:

I - garantir que todos os estudantes dos sistemas públicos de ensino estejam alfabetizados, em Língua Portuguesa e em Matemática, até o final do $3^{\circ}$ ano do ensino fundamental;

II - reduzir a distorção idade-série na Educação Básica;

III - melhorar o Î́ndice de Desenvolvimento da Educação Básica (IDEB);

IV - contribuir para o aperfeiçoamento da formação dos professores alfabetizadores;

V - construir propostas para a definição dos direitos de aprendizagem e desenvolvimento das crianças nos três primeiros anos do ensino fundamental. (BRASIL, 2012c). 
Para que tais objetivos sejam atingidos, é necessária a pactuação federativa e a dinamização de ações que envolvam a formação docente continuada dos professores que atuam nos três primeiros anos do ensino fundamental. Para tal formação, há a concessão de bolsas de apoio - em diferentes níveis e escalas, para diferentes sujeitos e com distintas intenções.

A Portaria $\mathrm{n}^{\mathrm{o}}$ 1.458, de 14 de dezembro de 2012 (BRASIL, 2012d), é responsável por definir categorias e parâmetros para a concessão das bolsas de estudo e pesquisa no âmbito do Pacto Nacional pela Alfabetização na Idade Certa, na forma do art. 2 o, inciso I, da Portaria MEC nº 867, de 4 de julho de 2012 (BRASIL, 2012c).

$\mathrm{O}$ art. $3^{\circ}$ do mesmo documento legal indica que: "a Formação Continuada de Professores Alfabetizadores, ofertada por instituições de ensino superior (IES) formadoras definidas pelo MEC, será ministrada aos orientadores de estudo que, por sua vez, serão os responsáveis pela formação dos professores alfabetizadores. (BRASIL, 2012d).

No processo de formação há a ideia do uso de multiplicadores (art. $7^{\circ}$, inciso II da Portaria $\mathrm{n}^{\text {o }}$ 867, de 04/07/2012 (BRASIL, 2012c) que, em diferentes esferas, organizariam e repassariam o conteúdo formativo. Na perspectiva dos multiplicadores (difusores, divulgadores, repassadores [...]), o professor - de sala de aula - não tem contato direto com a Instituição de Ensino Superior responsável pela formação, mas sim através de orientadores de estudo escolhidos previamente nas redes de ensino, exercendo papel de difusores do conhecimento.

O curso será presencial, com duração de dois anos - carga horária de 120 horas anuais, de acordo com o Programa Pró-Letramento. Quem comandará os encontros entre os docentes serão os orientadores de estudo. Esses orientadores, que são professores das redes de ensino, terão de fazer um curso específico de 200 horas anuais em universidades públicas que participam do pacto. O MEC recomenda que eles sejam escolhidos entre os tutores do Pró-Letramento. (UNDIME, [S.d.]).

Além da centralização do processo formativo, o MEC também concentra o material instrucional oficial, pois os entes federados - estados e municípios - que aderirem ao Pacto acessarão do MEC os seguintes materiais: 
I. Cadernos de apoio para os professores matriculados no curso de formação; II. Livros didáticos de $1^{\circ}, 2^{\circ}$ e $3^{\circ}$ anos do ensino fundamental e respectivos manuais do professor, a serem distribuídos pelo Programa Nacional do Livro Didático (PNLD) para cada turma de alfabetização; III. Obras pedagógicas complementares aos livros didáticos distribuídos pelo PNLD - Obras complementares para cada classe de alfabetização; IV. Jogos pedagógicos para apoio à alfabetização para cada turma de alfabetização; V. Obras de referência, de literatura e de pesquisa distribuídas pelo Programa Nacional Biblioteca da Escola (PNEB) para cada turma de alfabetização; VI. Obras de apoio pedagógico aos professores, distribuídas por meio do PNEB para os professores; VII. Tecnologias educacionais de apoio à alfabetização para as escolas. (BRASIL, 2012b, p.31).

Com base nas análises até aqui encetadas, é possível perceber que o Pacto promove dois movimentos: por um lado, centraliza todos os esforços teóricos de compreensão da alfabetização, construindo parâmetros considerados válidos e legítimos, seja no momento em que avaliza determinadas Instituições de Ensino Superior a promoverem cursos de formação para orientadores de estudo, seja no momento em que repassa material aos demais entes federados. De outra maneira, o pacto empodera sujeitos na esfera local: os orientadores de estudos (BRASIL, 2012b), ao mesmo tempo em que deslegitima a concepção de professor como intelectual, subordinando-o a outro sujeito, pretensamente porta-voz da formação necessária, reconhecida e legitimada, uma vez que a metodologia de formação indica o uso de difusores.

Esse mesmo professor que parece não ter a chance de discutir academicamente a formação que está recebendo - visto que são os orientadores de estudo e, mais especificamente, o coordenador local que tem acesso a IES -, é o mesmo que será responsabilizado nominalmente pelo resultado do seu trabalho em relação ao processo de alfabetização discente.

Serão três medidas nesse âmbito. A avaliação processual, por exemplo, será discutida nos cursos de formação. Ela pode ser realizada pelo docente em sala de aula, de forma interna. Também haverá um sistema informatizado para inserir os resultados da Provinha Brasil de cada criança, o que deve ser feito pelos professores - antes, os resultados ficavam conhecidos apenas dentro da escola. Por fim, o Inep vai aplicar em todas as turmas de concluintes do $3^{\circ}$ ano, uma avaliação externa universal. A ideia é medir o nível de alfabetização ao final do ciclo. A responsabilidade - e, portanto, os custos - é do MEC. (UNDIME, [S.d.]).

Há, ainda, outras duas situações associadas às estratégias do Pacto e que suscitam reflexões. Primeiro, a concepção de alfabetização restrita expressa na proposta inicial do Pacto e referendada pela ANA. Considerando que, tanto a Portaria $n^{\circ} 482$, de 
7 de junho de 2013 (BRASIL, 2013b), quanto a Portaria $n^{\circ}$ 867, de 4 de julho de 2012 (BRASIL, 2012c) destacam que a alfabetização é compreendida como restrita as áreas de língua portuguesa e matemática, a própria avaliação em larga escala que subsidia o Pacto - a ANA (BRASIL, [S.d.]) -, é “[...] incoerente com a proposta de formação integral da criança em processo de alfabetização prevista no PNAIC ao prever testes calcados apenas em Língua Portuguesa e Matemática”. (SILVA, 2016, p.181).

A ANA (BRASIL, [S.d.]) insere-se no contexto das avaliações nacionais de larga escala, regulamentadas no contexto do Sistema de Avaliação da Educação Básica (SAEB), configurado a partir de um conjunto de avaliações em larga escala vinculado ao Instituto Nacional de Pesquisas Educacional Anísio Teixeira (INEP): a Avaliação Nacional do Rendimento Escolar (ANRESC) ou Prova Brasil; a Avaliação Nacional da Educação Básica (ANEB) e a Avaliação Nacional de Alfabetização (ANA). Recentemente o sistema de avaliação foi objeto de um duplo movimento político. No dia 5 de maio de 2016, a Portaria no 369 do Ministério da Educação (MEC) (BRASIL, 2016a) instituiu o Sistema Nacional de Avaliação da Educação Básica (Sinaeb). Todavia, em 25 de agosto de 2016, a portaria $n^{\circ} 981$ retomou o Saeb (BRASIL, 2016b) em sua fórmula anterior.

Uma segunda situação associada vem da proposição de alfabetização até os 8 anos de idade ou até o final do $3^{\circ}$ ano do ensino fundamental. Nem o Decreto 6.094/2007 (BRASIL, 2007), tampouco a Portaria $n^{\circ}$ 867/2012 (BRASIL, 2012c) mencionam - a despeito da propaganda institucional do Pacto -, a universalização da alfabetização. Ambas as legislações informam o compromisso com a alfabetização 'das' crianças e não de 'todas' as crianças. Algo aparentemente semântico evoca a brecha no pacto para a possibilidade de algumas dessas crianças não lograrem êxito no processo de alfabetização.

\section{O Pacto, a alfabetização e o accountability}

Nos estudos de políticas educacionais, enquadramos as estratégias e objetivos do Pacto como uma ação governamental. A ação governamental empresta materialidade às políticas educacionais, não sendo, de forma alguma, neutra, uma vez que "[...] reflete escolhas em um quadro de conflito, não havendo, portanto, governos imparciais, pois as 
escolhas sempre envolverão julgamento de valor, ainda que estejam ancoradas em avaliações técnicas". (OLIVEIRA; DUARTE, 2005, p.283).

As estratégias adotadas pelo Pacto tem uma intenção altamente meritória: alfabetizar crianças até o terceiro ano do ensino fundamental, tomando a alfabetização “[...] como processo de aquisição da 'tecnologia da escrita', isto é, do conjunto de técnicas - procedimentos, habilidades - necessárias para a prática da leitura e da escrita”. (SOARES, 2004, p.91).

Todavia as ações do Pacto parecem convergir para um processo de responsabilização docente. Em que pese a condição inata de responsabilidade do professor ante aos processos pedagógicos sob sua regência, o PNAIC suscita uma responsabilização direta desse professor aos resultados aferidos por sua turma nas avaliações em larga escala. A questão é: até que ponto essa responsabilização direta também não será unilateral, desconsiderando todas as variáveis implicadas no processo de alfabetização?

Além do mais, a sistemática de avaliação do andamento das ações do PNAIC deixa clara uma perspectiva de controle descendente, que vincula desempenho ao recebimento de aporte financeiro - bolsa, criando uma lógica de rede onde o professor avalia - mas depende da avaliação - do seu orientador de estudos para receber sua bolsa $[\ldots]$.

Para a efetivação do processo de formação, bem como autorização para recebimento de bolsas de estudo e pesquisa aos participantes da Formação Continuada no âmbito do Pacto Nacional pela Alfabetização na Idade Certa, cada participante deverá atender ao seguinte cronograma mensal:

15 a 17: avaliação dos perfis municipais: professor alfabetizador avalia o orientador e este avalia o professor alfabetizador e o coordenador local;

18 a 20: coordenador local avalia seus orientadores;

20 a 26: avaliação dos perfis da universidade;

27 a 30: aprovação das avaliações pelo coordenador adjunto e coordenador IES;

1 a 3 - mês seguinte: autorização de pagamento pelo coordenador IES. Os critérios utilizados para a avaliação são: Frequência, Atividades realizadas e Monitoramento. O critério Monitoramento é referente à execução da avaliação do próprio perfil no sistema. (BRASIL, 2015a, p.12).

Ao mesmo tempo em que providencia formação docente continuada para os professores alfabetizadores - aliás, nenhum agente público, redes ou sistemas de ensino 
faz mais do que sua obrigação legal em fornecer formação docente continuada (BRASIL, 1996, artigos 67 e 87), o Pacto evoca certa relação causa-consequência, atribuindo protagonismo ao professor pelos resultados da aprendizagem dos seus alunos, até porque o professor é o sujeito de responsabilização direta, pois se trata de um sujeito com nome e sobrenome.

Gatti (2012) afirma que “[...] o trabalho do professor não se esgota na escola: faz-se presente o tempo todo, em cada dia dos professores, em tarefas externas à escola e em preocupações que não se trancam na saída da escola" (GATTI, 2012, p.435), dentre tais preocupações, figuram questões como o rendimento e aprendizagem dos seus alunos. Ele já se sente suficientemente responsabilizado e mais, acalenta certa tendência a assumir para si qualquer culpa.

Em que pese o fato de que o professor é, por princípio e por condição profissional, responsável pela aprendizagem dos alunos, é interessante observar que o processo de aprendizagem ocorre por uma correlação multifatorial onde o professor é um (importante) componente. Mas, qual o limite entre a prática da formação docente continuada como estratégia de emancipação ou como repasse do accountability?

[...] discutir formação de professoras alfabetizadoras na atualidade exige considerar a constituição multifacetada da profissionalidade docente, as formas de organização das instituições escolares, aspectos históricos do fenômeno alfabetização em suas variadas acepções e as políticas públicas para a educação demandadas por organismos internacionais com forte influência sobre a ação docente [...] a profissionalidade docente, concebida como um fenômeno social, é complexa e exige aprofundamentos que perpassam aspectos formativos, culturais, históricos, políticos e econômicos. (AGUIAR, 2011, p.566).

A Portaria $\mathrm{n}^{\mathrm{o}}$ 867, de 4 de julho de 2012 (BRASIL, 2012c), que institui o PNAIC, ratifica o compromisso assumido no âmbito do Decreto 6.094/2007 (BRASIL, 2007) - Plano de Metas Compromisso Todos pela Educação - com a alfabetização das

[...] crianças até, no máximo, os oito anos de idade, ao final do $3^{\circ}$ ano do ensino fundamental, aferindo os resultados por exame periódico específico, que passa a abranger: [...] II - a realização de avaliações anuais universais, pelo Instituto Nacional de Estudos e Pesquisas Educacionais Anísio Teixeira - INEP, para os concluintes do $3^{\circ}$ ano do ensino fundamental. (BRASIL, 2012c). 
A Medida Provisória $n^{\circ}$ 586/2012 (BRASIL, 2012a), exarada meses após a Portaria $\mathrm{n}^{\circ}$ 867, menciona o apoio financeiro às ações do PNAIC através do Fundo Nacional de Desenvolvimento da Educação - FNDE, por meio do “Art. 2 $2^{\circ}$ [...] II reconhecimento dos resultados alcançados pelas escolas e pelos profissionais da educação no desenvolvimento das ações do Pacto Nacional pela Alfabetização na Idade Certa". (BRASIL, 2012c).

Nessa direção, o PNAIC emparelha-se a instrumentos de accountability, “[...] pois, que a ideia contida na palavra accountability traz implicitamente a responsabilização pessoal pelos atos praticados e explicitamente a exigente prontidão para a prestação de contas, seja no âmbito público ou no privado". (PINHO; SACRAMENTO, 2009, p.1347).

O Pacto tem uma fórmula de responsabilização bastante evidente: tracejo de meta (alfabetização de todas as crianças até os 8 anos de idade) versus aporte técnico e financeiro (estabelecimento de rotas e métodos formativos, associados a bolsas de apoio) versus cobrança de resultados (desempenho em avaliações em larga escala).

Trata-se de responsabilização, de prestação de contas social, uma vez que [...]

Buscando uma síntese, accountability encerra a responsabilidade, a obrigação e a responsabilização de quem ocupa um cargo em prestar contas segundo os parâmetros da lei, estando envolvida a possibilidade de ônus, o que seria a pena para o não cumprimento dessa diretiva. (PINHO; SACRAMENTO, 2009, p.1348).

A questão que talvez deva orientar o debate é: quem deve ser responsabilizado? O estado, que falhou historicamente em obter resultados positivos em suas ações? Ou o professor, promovido compulsoriamente a protagonista do momento histórico?

Quanto à meta de alfabetizar [...] as crianças até os oito anos de idade, definida pelo programa como idade certa, verificamos o reconhecimento de que a escola e, portanto, o próprio Estado, não tem dado conta de oferecer a todas as crianças, de forma equitativa, um direito fundamental de se alfabetizar até os oito anos de idade. (SILVA, 2016, p.179).

Considerando que "[...] alfabetizar é possibilitar à criança o entendimento do mundo, pois as práticas sociais de leitura e escrita estão presentes na vida cotidiana de praticamente toda sociedade" (PEREIRA, 2012, p.50), toda ação de fomento ao processo constitui-se, em última instância, em uma ação de cidadania e emancipação. 
Porém este ato de emancipação cai, por vezes, na retórica da responsabilização pelas falhas, retirando do foco questões importantes.

A responsabilização na educação básica brasileira vem ocorrendo em detrimento da melhoria de elementos estruturais relacionados ao processo educacional, tornando-se apenas um procedimento de racionalização dos recursos existentes, sem aportar investimentos substanciais às escolas. (PASSONE, 2014, p.443).

De acordo com Soares (2003, p.91) alfabetização designa “[...] o processo pelo qual se adquire o domínio de um código e das habilidades de utilizá-lo para ler e escrever, ou seja: o domínio da tecnologia - do conjunto de técnicas - para exercer a arte e ciência da escrita". Assim a alfabetização é entendida como o uso social da língua em práticas de leitura e escrita, é lícito interpretar que "[...] a alfabetização implica desde sua gênese, a constituição do sentido, desse modo, implica, mais profundamente, uma forma de interação com o outro pelo trabalho de escritura" (SMOLKA, 2012, p.69), sendo que essa interação ocorre de maneira integral e ontológica.

Compreendendo que o método de alfabetização é o somatório de ações embasadas “em [...] princípios e hipóteses psicológicas, linguísticas, pedagógicas, que respondem a objetivos determinados. [Assim] o método será, pois o resultado da determinação dos objetivos a atingir (conceitos, habilidades, atitudes que caracterizarão a pessoa alfabetizada)" (SOARES, 2004, p.93), será possível que um método - por melhor e mais ancorado teoricamente - seja capaz de dar conta das condições reais e históricas dos processos de alfabetização em todo o Brasil?

Importante destacar que no primeiro momento de criação dos sistemas de avaliação de larga escala, e neste caso estamos falando especificamente do Saeb, os resultados obtidos e divulgados não encontraram eco nos municípios, muito menos nas escolas, uma vez que eles não se viam nos resultados. É a partir dessa constatação que em 2005, o Saeb vai passar por uma significativa reestruturação, permitindo a implantação de forma definitiva de uma política de accountability no país. (VIEIRA; VIDAL, 2011, p.425).

Com o PNAIC os municípios e as escolas passam a ser o centro da prestação de contas. O professor alfabetizador tem nome, sobrenome e CPF cadastrado junto ao MEC. Ele não pode 'ocultar-se' na multidão e tampouco dividir com outros a 
responsabilidade sobre os resultados alcançados por seus alunos. Trata-se do accountability aplicado a uma política educacional.

\section{Conclusões}

O Pacto Nacional pela Alfabetização na Idade Certa - PNAIC consiste em uma ação governamental que mobiliza o regime de colaboração, evocando os artigos 211 e 214 da Constituição Federal de 1988 (BRASIL, 1988).

Com a condução centralizada no MEC, as estratégias do PNAIC partem da formação docente continuada - com uso de difusores -, cuja responsabilização social ou prestação de contas é medida em avaliações em larga escala, mormente através da ANA - Avaliação Nacional de Alfabetização.

Parte de uma concepção que prioriza a língua portuguesa e a matemática como caminhos de alfabetização legando, em médio prazo, a introdução de outros saberes/disciplinas/campos do conhecimento ao processo de formação e de avaliação.

O Pacto tem uma fórmula de responsabilização bastante evidente: tracejo de meta (alfabetização das crianças até os 8 anos de idade) versus aporte técnico e financeiro (estabelecimento de rotas e métodos, associada a bolsas de apoio) versus cobrança de resultados (desempenho em avaliações em larga escala).

O Pacto, sob o ponto de vista de uma análise de políticas educacionais, promove ainda dois movimentos: por um lado, centraliza todos os esforços teóricos de compreensão da alfabetização, construindo parâmetros considerados válidos e legítimos, e empodera sujeitos na esfera local: os orientadores de estudos, ao mesmo tempo em que deixa implícita certa deslegitimação ante a concepção de professor como intelectual, subordinando-o a outro sujeito, porta-voz da formação necessária e reconhecida (oficial).

Assumimos que o Pacto apresenta mecanismos que emparelham a formação docente continuada como estratégia de repasse do accountability, colocando o professor como coadjuvante do processo de formação, mas como protagonista da responsabilização e cobrança de resultados. 


\section{REFERÊNCIAS}

AGUIAR, M. A. L. A formação da alfabetizadora. In: SIMPÓSIO INTERNACIONAL DE ENSINO DA LÍNGUA PORTUGUESA, 1, n.1, 2011, Uberlândia. Anais... Uberlândia: EDUFU, 2011. Disponível em: <http://www.ileel.ufu.br/anaisdosielp/wpcontent/uploads/2014/06/volume_1_artigo_061.pdf>. Acesso em: 24 mai. 2016.

BARDIN, L. Análise de conteúdo. Lisboa : Edições 70, 2007.

BRASIL. ANA - Avaliação Nacional da Alfabetização. Brasília: INEP, [S.d.]. Disponível em: <http://provabrasil.inep.gov.br/ana>. Acesso em: 16 dez. 2016.

BRASIL. (1988). Constituição da República Federativa do Brasil. Brasília: Senado Federal, 1988.

BRASIL. Ministério da Educação. Decreto 6.094, de 24 de abril de 2007. Dispõe sobre a implementação do Plano de Metas Compromisso Todos pela Educação, pela União Federal, em regime de colaboração com Municípios, Distrito Federal e Estados, e a participação das famílias e da comunidade, mediante programas e ações de assistência técnica e financeira, visando a mobilização social pela melhoria da qualidade da educação básica. Brasília: Senado Federal, 2007. Disponível em: <http://www.planalto.gov.br/ccivil_03/_ato2007-2010/2007/decreto/d6094.htm>. Acesso em: 24 mai. 2016.

BRASIL. Ministério da Educação. Decreto no 6.755, de 29 de janeiro de 2009. Institui a Política Nacional de Formação de Profissionais do Magistério da Educação Básica, disciplina a atuação da Coordenação de Aperfeiçoamento de Pessoal de Nível Superior CAPES no fomento a programas de formação inicial e continuada, e dá outras providências. - Revogado pelo Decreto $n^{\circ}$ 8.752, de 2016. Brasília: Senado Federal, 2009. Disponível em: <https://www.planalto.gov.br/ccivil_03/_ato20072010/2009/decreto/d6755.htm>. Acesso em: 24 mai. 2016.

BRASIL. Ministério da Educação. Decreto no 7.084, de 27 de janeiro de 2010. Dispõe sobre os programas de material didático e dá outras providências. Brasília: Senado Federal, 2010. Disponível em: <http://www.planalto.gov.br/ccivil_03/_Ato20072010/2010/Decreto/D7084.htm>. Acesso em: 24 mai. 2016.

BRASIL. Ministério da Educação. Lei no 9.394/96, de 20 de dezembro de 1996. Estabelece as Diretrizes e Bases da Educação Nacional. Brasília: Senado Federal, 1996. Disponível em: <http://www.planalto.gov.br/ccivil_03/leis/19394.htm>. Acesso em: 30 abr. 2016.

BRASIL. Ministério da Educação. Lei n⿳ 11.273, de 6 de fevereiro de 2006. Autoriza a concessão de bolsas de estudo e de pesquisa a participantes de programas de formação inicial e continuada de professores para a educação básica. Brasília: Senado Federal, 2006a. Disponível em: <http://www.planalto.gov.br/ccivil_03/_Ato20042006/2006/Lei/L11273.htm>. Acesso em: 24 mai. 2016. 
BRASIL. Ministério da Educação. Medida provisória no 586 de 8 de novembro de 2012. Dispõe sobre o apoio técnico e financeiro da União aos entes federados no âmbito do Pacto Nacional pela Alfabetização na Idade Certa e, dá outras providências. Brasília: Ministério da Educação, 2012a.

BRASIL. Ministério da Educação. Pacto Nacional pela alfabetização na idade certa. Documento orientador das ações de formação continuada de professores alfabetizadores em 2015. Brasília: Ministério da Educação, 2015a. Disponível em: <http://pacto.mec.gov.br/images/pdf/Formacao/documento_orientador_2015_versao_sit e.pdf>. Acesso em: 13 dez. 2016.

BRASIL. Ministério da Educação. Pacto Nacional pela alfabetização na idade certa. Toda criança alfabetizada até os oito anos. Documento de Apresentação. Brasília: Ministério da Educação, 2012b. Disponível em: <http://pacto.mec.gov.br/images/pdf/pacto_livreto.pdf >. Acesso em: 26 mai. 2016.

BRASIL. Ministério da Educação. Portaria n⿳0 90, de 6 de fevereiro de 2013. Define o valor máximo das bolsas para os profissionais da educação participantes da formação continuada de professores alfabetizadores no âmbito do Pacto Nacional pela Alfabetização na Idade Certa. Brasília: Ministério da Educação, 2013a. Disponível em: <http://pacto.mec.gov.br/images/pdf/portaria90_6_fevereiro_2013.pdf>. Acesso em: 22 mai. 2016.

BRASIL. Ministério da Educação. Portaria no 369, de 05 de maio de 2016. Institui o Sistema Nacional de Avaliação da Educação Básica - SINAEB. Brasília: Ministério da Educação, 2016a. Disponível em: <http://www.jusbrasil.com.br/diarios/115170144/dousecao-1-06-05-2016-pg-26>. Acesso em: 23 set. 2016.

BRASIL. Ministério da Educação. Portaria no 482, de 7 de junho de 2013. Dispõe sobre o Sistema de Avaliação da Educação Básica - SAEB. Brasília: Ministério da Educação, 2013b. Disponível em: $<$ http://download.inep.gov.br/educacao_basica/prova_brasil_saeb/legislacao/2013/porta ria_n304_saeb_RevFC.pdf>. Acesso em: 23 mai. 2016.

BRASIL. Ministério da Educação. Portaria no 867, de 4 de julho de 2012 - Institui o Pacto Nacional pela Alfabetização na Idade Certa e as ações do Pacto e define suas diretrizes gerais. Diário Oficial da União, Brasília, DF, 5 jul. 2012c.

BRASIL. Ministério da Educação. Portaria n⿳ 981, de 25 de agosto de 2016. Revoga a portaria MEC $\mathrm{n}^{\circ} 369$, de 05 de maio de 2016, e dá outras providências. Brasília: Ministério da Educação, 2016b. Disponível em: $<$ http://portal.mec.gov.br/index.php?option=com_docman\&view=download\&alias $=476$ 21-portaria-981-02set-pdf\&category_slug=agosto-2016-pdf\&Itemid=30192>. Acesso em: 23 set. 2016.

BRASIL. Ministério da Educação. Portaria n⿳ 1.458, de 14 de dezembro de 2012 , Brasília: Ministério da Educação, 2012d. Disponível em: <http://pacto.mec.gov.br/images/pdf/port_1458_141212.pdf >. Acesso em: 26 mai. 2016. 
BRASIL. Ministério da Educação. Pró-letramento: Programa de formação continuada de professores da educação básica: alfabetização e linguagem. Brasília: MEC/SEB/SEED, 2006b.

BRASIL. Ministério da Educação. Programa de formação de professores alfabetizadores: documento de apresentação. Brasília: Ministério da Educação, Secretaria da Educação Fundamental, 2001. Disponível em <http://portal.mec.gov.br/seb/arquivos/pdf/Profa/guia_for_1.pdf>. Acesso em: 23 jun. 2016.

BRASIL. Ministério da Educação. Resolução/CD/FNDE no 4, de 27 de fevereiro de 2013. Estabelece orientações e diretrizes para o pagamento de bolsas de estudo e pesquisa para a Formação Continuada de Professores Alfabetizadores, no âmbito do Pacto Nacional pela Alfabetização na Idade Certa. Brasília: FNDE, 2013c. Disponível em:

$<$ https://www.fnde.gov.br/fndelegis/action/UrlPublicasAction.php?acao=abrirAtoPublic o\&sgl_tipo $=$ RES\&num_ato $=00000004 \&$ seq_ato $=000 \& v 1 r \_a n o=2013 \&$ sgl_orgao $=F N D$ E/MEC>. Acesso em: 16 dez. 2016.

BRASIL. Ministério da Educação. Resolução/CD/FNDE n⿳ 10, de 4 de dezembro de 2015. Estabelece orientações, critérios e procedimentos para a operacionalização da assistência financeira aos estados das regiões Norte e Nordeste para impressão de material de formação e apoio à prática docente, com foco na aprendizagem do aluno da educação básica. Brasília: FNDE, 2015. Disponível em:

<https://www.fnde.gov.br/fndelegis/action/UrlPublicasAction.php?acao=abrirAtoPublic o\&sgl_tipo $=$ RES\&num_ato $=00000010 \& s e q \_a t o=000 \& v l r \_a n o=2015 \& s g 1 \_$orgao $=C D /$ FNDE/MEC>. Acesso em: 16 dez. 2016.

BRASIL. Ministério da Educação. Resolução/CD/FNDE n 12, de 8 de maio de 2013. Altera dispositivos da Resolução CD/FNDE nº 4, de 27 de fevereiro de 2013, que estabelece orientações e diretrizes para o pagamento de bolsas de estudo e pesquisa para a Formação Continuada de Professores Alfabetizadores, no âmbito do Pacto Nacional pela Alfabetização na Idade Certa. Brasília: FNDE, 2013d. Disponível em: $<$ https://www.fnde.gov.br/fndelegis/action/UrlPublicasAction.php?acao=abrirAtoPublic o\&sgl_tipo $=$ RES\&num_ato $=00000012 \&$ seq_ato $=000 \& v 1 r \_a n o=2013 \& s g 1$ orgao $=C D /$ FNDE/MEC>. Acesso em: 16 dez. 2016.

GATTI, B. A. Formação de professores e profissionalização: contribuições dos estudos publicados na RBEP entre 1998 e 2011. Revista Brasileira de Estudos Pedagógicos, Brasília, v.93, n.234, p.423-442, mai./ago. 2012. Número especial.

OLIVEIRA, D. A.; DUARTE, A. Política educacional como política social: uma nova regulação da pobreza. Perspectiva, Florianópolis, v.23, n.2, p.279-301, jul./dez. 2005.

PASSONE, E. F. K. Incentivos monetários para professores: avaliação, gestão e responsabilização na Educação Básica. Cadernos de Pesquisa, São Paulo, v.44, n.152, p.424-448, abr./jun. 2014. 
PEREIRA, C. J. T. A formação do professor alfabetizador: desafios e possibilidades na construção da prática docente. 2012. 130 f. Dissertação (Mestrado em Educação) Universidade Federal de Rondônia, Porto Velho, 2012.

PINHO, J. A. G.; SACRAMENTO, A. R. S. Accountability: já podemos traduzi-la para o português? Revista de Administração Pública, Rio de Janeiro, v.43, n.6, p.13431368, dez. 2009.

SILVA, C. C. F. O Pacto Nacional pela alfabetização na idade certa - PNAIC: entre méritos e críticas de uma política educacional. Crítica Educativa, Sorocaba, v.2, n.1, p.178-185, jan./jun. 2016.

SMOLKA, A. L. B. A criança na fase inicial da escrita: a alfabetização como processo discursivo. 13.ed. São Paulo: Cortez, 2012.

SOARES, M. Alfabetização e letramento. 2.ed. São Paulo: Contexto, 2004.

SOARES, M. Letramento e escolarização. In: RIBEIRO, V. M. (Org.). Letramento no Brasil. São Paulo: Global, 2003. p.89-115.

UNDIME. Entenda como funciona o Pacto Nacional pela alfabetização na idade certa. Belo Horizonte: UNDIME MG, [S.d.]. Disponível em: $<$ http://www.undimemg.org.br/noticias/entenda-como-funciona-o-pacto-nacional-pelaalfabetizacao-na-idade-certa/>. Acesso em: 22 jun. 2016.

VIEIRA, S.; VIDAL, E. Gestão educacional e resultados no IDEB: um estudo de caso em dez municípios cearenses. Estudos em Avaliação Educacional, São Paulo, v.22, n.50, p.419-434, set./dez. 2011.

\section{Como referenciar este artigo}

ESQUINZANI, Rosimar Serena Siqueira. O Pacto Nacional pela Alfabetização na Idade Certa e a responsabilização (accountability) do professor alfabetizador. Revista IberoAmericana de Estudos em Educação, Araraquara, v.11, n. esp. 4, p. 2465-2482, 2016. Disponível em:〈http://dx.doi.org/10.21723/riaee.v11.n.esp4.9203>. E-ISSN: 19825587.

Submetido em: setembro/2016

Aprovado em: novembro/2016 